\title{
Desempenhos produtivo e reprodutivo de um rebanho F1 Holandês x Gir em Minas Gerais
}

[Productive and reproductive performances of F1 Holstein x Gir cows in the state of Minas Gerais]

\author{
L.S. Ribeiro ${ }^{1}$, T.J.F. Goes ${ }^{2}$, R.A. Torres Filho ${ }^{2}$, C.V. Araújo ${ }^{3}$, R.B. Reis ${ }^{1}$, H.M. Saturnino ${ }^{1}$ \\ ${ }^{1}$ Universidade Federal de Minas Gerais - UFMG - Belo Horizonte, MG \\ ${ }^{2}$ Universidade Federal Fluminense - Niterói, RJ \\ ${ }^{3}$ Universidade Federal do Mato Grosso - UFMT - Sinop, MT
}

\begin{abstract}
RESUMO
Objetivou-se avaliar os desempenhos produtivo e reprodutivo de vacas F1 Holandês x Gir Minas Gerais, as quais foram mantidas em sistema de produção a pasto no verão, com suplementação de concentrado, e, no inverno, alimentadas com cana-de-açúcar, polpa de citros e concentrado. As características avaliadas foram: idade ao primeiro parto, intervalo parto-primeiro serviço, período de serviço, intervalo de partos, permanência da matriz no rebanho, produção de leite total por lactação, duração da lactação, produção média diária, produções ajustadas a 280 dias e a 305 dias de lactação, produção de leite por intervalo de partos e curvas de lactação conforme ordem de partos, época de partos e período de serviço. A função gama incompleta foi utilizada para estimação dos parâmetros das curvas de lactação. As demais características foram analisadas utilizando-se modelos lineares mistos. O rebanho apresentou ótimo desempenho (6271,56kg de leite por lactação). As fêmeas F1 Holandês x Gir são boa alternativa para a produção de leite, desde que garantidas boas condições de manejo, alimentação do rebanho e utilização de matrizes oriundas de programas de cruzamento direcionados empregando-se critérios de melhoramento genético.
\end{abstract}

Palavras-chave: bovinos de leite, curva de lactação, rebanho mestiço, produção de leite

\begin{abstract}
The objective was to evaluate the productive and reproductive performances of F1 Holstein $x$ Gir cows in the state of Minas Gerais. The herd during the summer was managed in a pasture based production system with supplementation of concentrate according to milk production and in the winter it was fed with sugar cane, citrus pulp and concentrate. The characteristics evaluated were: age at first calving, calving to first service interval, service period, calving interval, permanence the cows in the herd, total milk production per lactation, lactation length, average milk daily, productions adjusted to 280 and to 305 days of lactation, milk production per calving interval, and lactation curves. The Incomplete Gamma function was used to estimate the parameters of lactation curves at parturition order, parturition epoch and service period. The other characteristics were analyzed using linear mixed models. The herd showed great performance $(6271,56 \mathrm{~kg}$ of milk per lactation). F1 Holstein $x$ Gir cows are a good alternative to milk production, as long as good conditions of handling and feeding are guaranteed, and the use of cows derived from breeding programs targeted using genetic improvement criteria.
\end{abstract}

Keywords: dairy cattle, lactation curve, herd crossbred, milk production

\section{INTRODUÇÃO}

Para driblar os desafios impostos pelo clima tropical à produção de leite, a utilização do gado mestiço Europeu x Zebu é uma alternativa, uma

Recebido em 25 de abril de 2016

Aceito em 10 de outubro de 2016

E-mail: lilianribeiro91@hotmail.com vez que consegue-se aliar o potencial produtivo do gado europeu especializado com os fatores de resistência do gado zebu, resultando em animais com melhor desempenho em características econômicas importantes, como eficiência reprodutiva, sobrevivência no rebanho, 
produção de leite e desenvolvimento corporal. Estima-se que as vacas Girolando contribuam com mais de $70 \%$ do leite produzido no país (Campos e Miranda, 2012). Segundo Prata et al. (2014), o cruzamento entre Holandês e Gir tem sido realizado há anos e representa importante ferramenta para o aumento das eficiências produtiva e reprodutiva, bem como para a adaptação dos animais às condições de clima tropical, por meio da expressão da heterose e do efeito da complementaridade, sendo os animais F1 Holandês x Gir os que apresentam o máximo de heterose. Com a crescente utilização de animais mestiços F1 Holandês $x$ Gir, é necessário estudar e destacar os desempenhos produtivo e reprodutivo dessa composição genética em diferentes sistemas de produção (Delgado et al., 2012; Balancin Júnior et al., 2014; Ruas et al., 2014; Borges et al., 2015).

O objetivo deste trabalho foi avaliar os desempenhos produtivo e reprodutivo de um rebanho de vacas F1 Holandês x Gir criadas em condições adequadas de manejo em Minas Gerais.

\section{MATERIAL E MÉTODOS}

Os dados são provenientes da fazenda Vargem Grande, localizada no município de Monsenhor Paulo, sul de Minas Gerais, coordenadas aproximadas $21^{\circ} 46^{\prime} \mathrm{S}$ e $45^{\circ} 30^{\prime} \mathrm{O}$. O clima da região é tropical de altitude, apresentando temperatura máxima média de $27,98^{\circ} \mathrm{C}$ e temperatura mínima média de $14,76^{\circ} \mathrm{C}$, pluviosidade média anual de 1490,6 $\mathrm{mm} \mathrm{e}$ umidade relativa média de $74,93 \%$ no período estudado (Banco..., 2016). Nessa propriedade, somente vacas F1 Holandês x Gir são utilizadas para exploração leiteira. A reposição das vacas F1 foi feita com animais F1 comprados quando bezerras. Após o ano de 2010, todas as bezerras F1 foram produzidas na própria fazenda, utilizando-se programa de fertilização in vitro (FIV). A propriedade trabalha com cerca de 100 vacas em lactação.

As bezerras e novilhas foram criadas em lotes em pastejo contínuo, em pastagem de Brachiaria sp. Nos períodos da seca (maio a outubro), foi fornecida mistura mineral completa - proteinado (35\% de proteína bruta) e, nos períodos das chuvas (novembro a abril), foi fornecida mistura mineral completa - energética $(20 \%$ de proteína bruta) com pequena proporção de ureia. A fazenda avaliada trabalha com conceito de dieta independente da época do ano e do volumoso oferecido. As dietas são calculadas para atender a exigência estimada pelo NRC (2001) (segundo o peso vivo do animal, dias em lactação e produção de leite). No período da seca, as vacas em lactação ficaram contidas em canzil na pista de alimentação, sendo oferecida a quantidade de cana, polpa de cítrus e concentrado segundo o lote do animal. A suplementação com concentrado (farelo de soja e milho moído, minerais e vitaminas) e com polpa de cítrus foi feita sobre a cana, sendo oferecida três vezes ao dia: após a ordenha da manhã, 11h e após a ordenha da tarde. Os animais permaneceram na pista de alimentação em cada um dos períodos por pelo menos três horas. Nos intervalos, foram levados para áreas de descanso ou piquetes com acesso a sombra e água. Sal mineralizado foi fornecido ad libitum. No período das chuvas, as vacas em lactação permaneceram em sistemas de pasto manejados intensivamente. Dois módulos de piquetes foram utilizados, sendo o primeiro composto por piquetes de Panicum maximum cv Mombaça e Pennisetum purpureum cv Napier, sempre utilizados por vacas no terço inicial e médio da lactação. Já o segundo módulo, formado por pastagem de Cynodon dactylon cv Tifton 85 , foi manejado com vacas do terço final de lactação, por já ter sido observado pelo proprietário menor consumo nessa pastagem em relação às outras. Em ambos os módulos, a taxa de lotação foi de 10UA por hectare. Sempre foi utilizado o critério de altura para entrada e saída nos piquetes, segundo a interceptação luminosa de $95 \%$. Foi realizada a suplementação com concentrado oferecido em pista de alimentação com os animais contidos em canzis também três vezes ao dia, logo após as ordenhas e às $11 \mathrm{~h}$.

A secagem das vacas ocorreu, em média, 60 dias antes do parto ou quando a produção de leite era inferior a $4 \mathrm{~kg} / \mathrm{dia}$. As ordenhas foram realizadas sem a presença da cria, em ordenhadeira mecânica e com o uso de ocitocina $\left(2,0 \mathrm{UI} / \mathrm{mL}\right.$. animal ${ }^{-1}$.ordenha $\left.{ }^{-1}\right)$, via endovenosa, em todos os animais, antes do acoplamento das teteiras, sendo utilizadas duas vezes ao dia, às cinco e às 14 horas. As avaliações da produção de leite foram realizadas com intervalos de aproximadamente 15 dias. 
Os dados calculados e analisados foram: idade ao primeiro parto (IPP), intervalo parto-primeiro serviço (IPPS), período de serviço (PS), intervalo de partos (IdP), permanência da matriz no rebanho, produção de leite total por lactação (PLT), duração da lactação (DL), produção de leite média diária (PMD), produções de leite ajustadas a 280 dias de lactação (PL280) e a 305 dias de lactação (PL305), produção de leite por intervalo de partos (PLIdP) e as curvas de lactação conforme ordem de partos, época de partos e período de serviço. Os dados para calcular os dados produtivos foram os registrados no período de 2007 a 2014 e para avaliar os parâmetros reprodutivos foram os dos anos de 2002 a julho de 2015, períodos considerados com coleta de dados confiável pelo proprietário. A PLT foi calculada utilizando-se a função:

$$
\mathrm{PLT}=(\mathrm{C} 1 * \mathrm{E} 1)+\sum_{\mathrm{i}=2}^{\mathrm{n}}\left(\left(\frac{\mathrm{Ci}+\mathrm{C}_{\mathrm{i}-1}}{2}\right) * \mathrm{Ei}\right),
$$

sendo $\mathrm{C} 1=$ quantidade de leite no primeiro controle, em kg; E1= intervalo entre o parto e o primeiro controle, em dias; $\mathrm{n}=$ número de controles; $\mathrm{Ci}=$ quantidade de leite em cada controle $(i=2,3,4, \ldots, n)$, em kg; e Ei= intervalo entre dois controles consecutivos, em dias. A PL280 e a PL305 foram calculadas por regressão linear em função da covariável duração da lactação.

Para definição das curvas de lactação, foi utilizado o modelo de Wood (1967), o qual utiliza a função gama incompleta: $\mathrm{PL}=a \mathrm{t}^{\mathrm{b}} \exp ^{\mathrm{ct}}$, em que: PL é a produção de leite $(\mathrm{kg})$ no tempo de lactação t (dias); a, b e c são parâmetros que representam, respectivamente, a produção inicial da vaca, a taxa média de aumento da produção até atingir o pico e a taxa média de declínio na produção após atingir o pico de lactação; e a base do logaritmo natural (constante $=2,7182)$. Para essa análise, foram excluídas lactações com primeiro controle após 20 dias de lactação, intervalo entre pesagens superior a 30 dias e animais com menos de sete controles leiteiros registrados (cerca de 100 dias de lactação). Visando ao melhor ajuste das curvas aos valores observados, representado pelo coeficiente de determinação $\left(\mathrm{R}^{2}\right)$, foram formadas classes intervaladas de 30 dias em lactação, utilizando-se a média de produção dos animais nessas classes. As análises foram realizadas mediante o uso do PROC NLIN do
SAS 9.0 (Statistical..., 2004). A produção de leite no pico $\left[\left(\left(a^{*}(b / c)^{b}\right) * \exp (-b)\right]\right.$, tempo até a ocorrência do pico (b/c) e a persistência da lactação [-((b+1)*lnc)] também foram estimadas. Para estimar as curvas de lactação em função da época do parto, os partos foram divididos entre: ocorridos nos meses de janeiro, fevereiro e março, ocorridos em abril, maio e junho, ocorridos em julho, agosto e setembro e ocorridos em outubro, novembro e dezembro. Já para as curvas em função do período de serviço, foram formadas classes de PS, sendo elas: PS até 90 dias, PS entre 91 e 120 dias, PS entre 121 e 150 dias, PS entre 151 e 180 dias e PS maior que 180 dias.

Para todas as análises, exceto para a análise de IPP, foi considerado um modelo geral que incluiu como efeitos fixos: a ordem de parto, o grupo de contemporâneo formado por ano e a estação de parto, o ano de parto e a época de parto, e, como efeito aleatório, o pai da vaca. Para as análises de produção de leite (PLT, PMD, PLIdP), a duração da lactação também foi considerada no modelo como covariável. Para a IPP, o grupo contemporâneo foi formado pelo ano e pela estação de nascimento da fêmea, e o modelo incluiu os efeitos fixos de ano de nascimento e a época de nascimento. Para o PS e o IPPS, foi incluída como efeito fixo adicional a utilização de protocolo de inseminação artificial a tempo fixo (IATF). As análises de variância foram realizadas usando-se o PROC GLM do SAS.

Foram utilizadas 613 lactações para a análise, excluindo os dados fora dos seguintes critérios: IPP entre 713 e 1250 dias, IPPS entre 20 e 200 dias, PS entre 20 e 300 dias, IdP entre 300 e 600 dias, produção total entre 1000 e $10600 \mathrm{~kg}$ e períodos de lactação entre 100 e 400 dias. A ordem de parto máxima foi fixada em nove. Foram observadas 11 ordens de parto superiores a nove, as quais foram incluídas na última classe, sendo elas: nove ordens de parto 10 e duas ordens de parto 11 .

\section{RESULTADOS E DISCUSSÃO}

As médias e os desvios-padrão das características estudadas estão apresentados na Tab. 1. Devido à compra de animais, nem todos os dados deles estavam completos. 
Desempenhos produtivo...

Tabela 1. Médias ajustadas e desvios-padrão das características avaliadas de um rebanho F1 Holandês x Gir

\begin{tabular}{|c|c|c|c|}
\hline Características & $\mathrm{n}$ & Média & Desvio-padrão \\
\hline \multicolumn{4}{|l|}{ Produção } \\
\hline $\mathrm{N}^{\mathrm{o}}$ de Partos & 997 & 6,26 & 2,38 \\
\hline PLT (kg) & 613 & 6271,56 & 967,91 \\
\hline DL (dias) & 613 & 283,02 & 49,85 \\
\hline PMD (kg) & 613 & 22,23 & 3,72 \\
\hline PL280 (kg) & 613 & 6206,93 & 967,74 \\
\hline PL305 (kg) & 613 & 6741,16 & 967,74 \\
\hline PLIdP (kg) & 480 & 16,91 & 3,07 \\
\hline \multicolumn{4}{|l|}{ Reprodução } \\
\hline IPP (meses) & 176 & 33,36 & 2,57 \\
\hline IPPS (dias) & 862 & 71,21 & 24,53 \\
\hline PS (dias) & 721 & 113,29 & 57,01 \\
\hline IdP (dias) & 666 & 394,58 & 59,66 \\
\hline
\end{tabular}

A média da idade ao primeiro parto foi de 33,36 meses (Tab. 1), estando um pouco superior à considerada ideal para fêmeas mestiças por Ferreira e Miranda (2007), a qual seria entre 30 e 32 meses. Mas, considerando a vida útil e a produção alcançada por esses animais, isso se torna irrelevante e é ainda inferior à média nacional de 42 meses para mestiças Holandês x Zebu. Balancin Júnior et al. (2014) encontraram 30,71 meses para fêmeas F1. A IPP foi influenciada pelo pai e pelo ano de nascimento (Tab. 2) .

O intervalo parto-primeiro serviço de 71,21 dias (Tab. 1) foi afetado pelo pai, pelo ano de parto, pela interação entre ano e época de parto e pelo uso de protocolo de IATF (Tab. 2). Com relação à utilização de protocolo, as vacas que não o utilizaram apresentaram os menores IPPS, sendo de 69,08 dias, enquanto naquelas em que se utilizou protocolo, o IPPS foi de 78,03 dias.

Tabela 2. Resumo da análise de variância para as características estudadas de um rebanho F1 Holandês x Gir

\begin{tabular}{|c|c|c|c|c|c|c|c|c|c|c|}
\hline & PLT & $\mathrm{DL}$ & PMD & PL280 & PL305 & PLIdP & IPP & IPPS & $\mathrm{OS}$ & IdP \\
\hline Pai & $* *$ & ns & $* *$ & $* *$ & $* *$ & $* *$ & $* *$ & $*$ & $* *$ & $* *$ \\
\hline Ano de parto & $* *$ & $* *$ & $* *$ & $* *$ & $* *$ & $* *$ & - & $* *$ & $* *$ & $* *$ \\
\hline Ano*Época de parto & ns & $*$ & $* *$ & ns & ns & ns & - & $*$ & $* *$ & $*$ \\
\hline Ordem de parto & $* *$ & ns & $* *$ & $* *$ & $* *$ & $* *$ & - & ns & $*$ & ns \\
\hline Época de nascimento & - & - & - & - & - & - & ns & - & - & - \\
\hline Ano*Época de nascimento & - & - & - & - & - & - & $*$ & - & - & - \\
\hline Protocolo de IATF & - & - & - & - & - & - & - & - & ns & - \\
\hline
\end{tabular}

** e * significativo a $1 \%$ e $5 \%$, respectivamente; ns = não significativo; $(-)$ = não avaliado.

PLT = produção leiteira total; DL = duração da lactação; PMD = produção de leite média diária; PL280 = produção de leite ajustada a 280 dias de lactação, PL305 = produção de leite ajustada a 305 dias de lactação; PLIdP = produção de leite por intervalo de partos; IPP = idade ao primeiro parto; IPPS = intervalo parto-primeiro serviço; PS = período de serviço; IdP = intervalo de partos; IATF = inseminação artificial a tempo fixo. 
A média do período de serviço de 113,29 dias (Tab. 1) está condizente com o considerado por Ferreira e Miranda (2007) de até 120 dias como aceitável para vacas mestiças a pasto. O PS foi afetado pela ordem de parto $(\mathrm{P}<0,05 ;$ Tab. 2$)$, com diferença entre as médias $(\mathrm{P}<0,05)$ no teste de Duncan, sendo de $114,20^{\mathrm{b}}(\mathrm{n}=164) ; 109,53^{\mathrm{b}}$ $(\mathrm{n}=140) ; 110,69^{\mathrm{b}} \quad(\mathrm{n}=133) ; 111,71^{\mathrm{b}} \quad(\mathrm{n}=105)$; $110,01^{\mathrm{b}}(\mathrm{n}=70) ; 118,61^{\mathrm{b}}(\mathrm{n}=56) ; 121,00^{\mathrm{b}}(\mathrm{n}=30)$; $132,67^{\mathrm{a}, \mathrm{b}}(\mathrm{n}=15)$ e $150,88^{\mathrm{a}}(\mathrm{n}=8)$ dias para as ordens de parto: 1, 2, 3, 4, 5, 6, 7, 8 e 9, respectivamente. As vacas com maior ordem de parto apresentaram os maiores PS. Esse resultado pode estar relacionado à maior produção de leite no pico e durante a lactação e, consequentemente, à maior exigência nutricional das multíparas, ocasionando atraso na reprodução. O PS médio das primíparas foi considerado adequado. Época de parto não afetou o PS (P>0,05), apesar de ter havido diferença numérica entre as médias, com 120,15 dias de período de serviço na estação das chuvas e 107,92 na estação seca do ano. Ruas et al. (2007) também observaram menor PS nas vacas que pariram na estação seca (132,02 dias) do que nas que pariram na estação chuvosa $(190,07$ dias), o que pode ser devido à maior disponibilidade energética na seca quando há suplementação, permitindo que o animal retorne à atividade ovariana mais rapidamente após o parto. Outra hipótese é a possibilidade de os animais terem passado por estresse calórico no período das estações chuvosas, nas quais ocorrem temperaturas e umidades mais elevadas. Ocorreu variação anual do PS.

O intervalo de partos (IdP) foi influenciado pelo pai da vaca $(\mathrm{P}<0,01)$, pelo ano de parto $(\mathrm{P}<0,01)$ e pela interação ano de parto e época de parto $(\mathrm{P}<0,05)$ (Tab. 2). A média do intervalo de partos de 394,58 dias (Tab. 1) está dentro do considerado por Ferreira e Miranda (2007) numa produção de leite a pasto, em que um intervalo de 14 meses é satisfatório. Houve variação do intervalo de partos entre os anos. A ordem de parto não afetou o $\operatorname{IdP}(\mathrm{P}>0,05)$, embora tenha afetado o PS $(\mathrm{P}<0,05)$ (Tab. 2).

A permanência média da matriz no rebanho foi de 6,26 lactações (Tab. 1). A média observada foi superior à apontada por Campos e Miranda (2012) para os países de pecuária leiteira mais desenvolvida, nos quais apenas $15 \%$ das vacas em lactação têm mais de cinco crias. Neste estudo, observou-se $58,79 \%$ das vacas com mais de cinco lactações. Lemos et al. (1996), que estudaram as características de sobrevivência de fêmeas mestiças Holandês x Guzerá, apontaram que as $\mathrm{F} 1$ foram descartadas com menor frequência e tiveram maior número de lactações, com 8,5 lactações em nível alto de manejo. Para Borges et al. (2015), vacas mestiças HxZ que recebem suporte nutricional adequado apresentam baixa taxa de descarte, menor taxa de mortalidade e maior longevidade no rebanho. Pesquisa apontou para a superioridade econômica das vacas F1 Holandês vermelho e branco x Guzerá. Os resultados mostraram a existência de importante heterose em produção de leite, fertilidade, mortalidade, vida útil e preço da vaca de descarte (Teodoro, 1996).

As produções de leite total, média e ajustada para 280 e 305 dias foram elevadas (Tab. 1), tendo sido afetadas por pai da vaca, ano do parto, época do parto e ordem do parto $(\mathrm{P}<0,01$; Tab. $2)$. Esse nível de produção pode ser comparado aos citados por Freitas et al. (2001) e Mellado et al. (2011), que avaliaram vacas da raça Holandês no Brasil, em sistema intensivo de produção. Não foi encontrada na literatura referência de rebanhos F1 Holandês x Gir com esse nível de produção. Segundo a Associação Brasileira de Criadores de Bovinos da Raça Holandesa (Relatório..., 2014), a média nacional das vacas Holandesas foi de $9567 \mathrm{~kg}$ em 305 dias de lactação, as quais são mantidas majoritariamente em sistema intensivo de produção. Considerando que o rebanho em estudo é mantido em sistema a pasto com suplementação estratégica, a produção apresentada é expressiva, superando a produção média dos rebanhos Girolando, que foi de $5220 \mathrm{~kg}$ em 305 dias em 2014, segundo a Associação Brasileira de Criadores de Girolando (Programa..., 2016), a qual reúne dados de rebanhos mantidos em diversos sistemas de manejo e de animais com composição genética variada. Tal resultado é justificado pelo trabalho de seleção genética que a propriedade faz há mais de 10 anos e pelo manejo que atende as necessidades do gado nesse nível de produção e permite que o rebanho expresse seu potencial genético.

Tanto a PLT como a PL280 e a PL305 aumentaram com a ordem de parto (Fig. 1), apresentando menores médias nas primeira e segunda lactações, atingindo as maiores 
produções a partir do terceiro parto e mantendose elevadas no oitavo e nono partos. Essa variação pode ser devido ao fato de, nos dois primeiros partos, as vacas ainda estarem em crescimento e, em razão disso, terem menos energia disponível para a produção de leite, além de a glândula mamária ainda estar em desenvolvimento na primeira lactação. Delgado et al. (2012) e Borges et al. (2015) encontraram resultados semelhantes, com aumento das produções de leite com o aumento das ordens de parto.

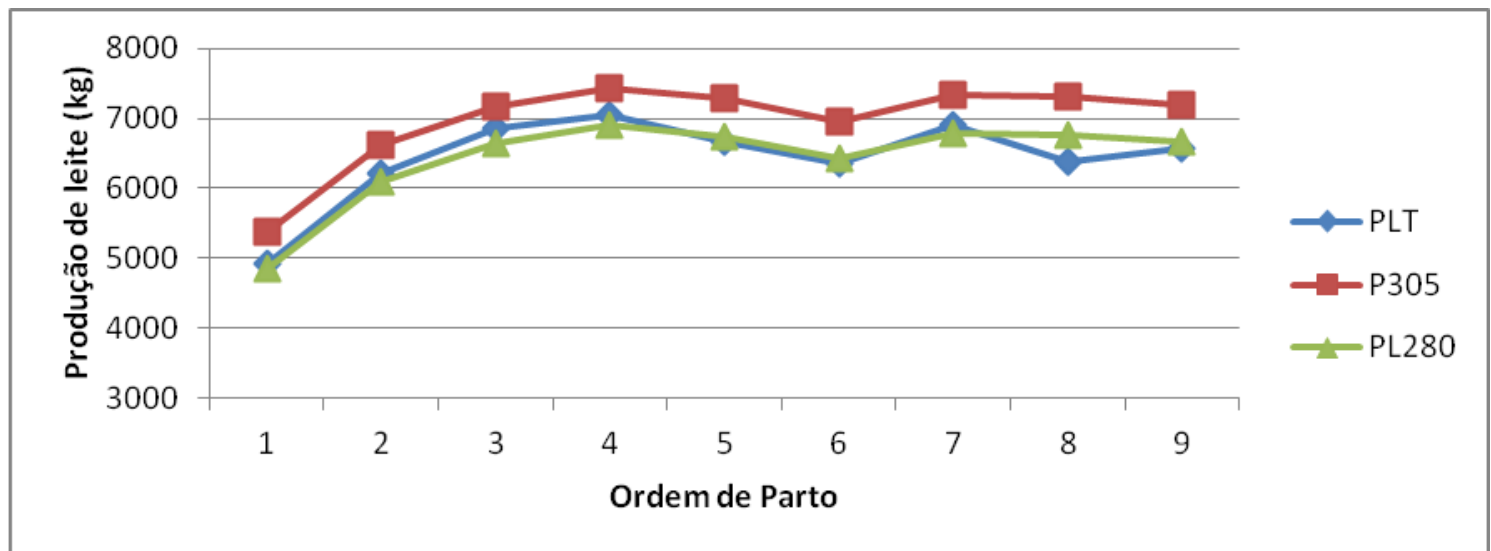

Figura 1. Produção de leite total (PLT), produção de leite ajustada a 280 dias de lactação (PL280) e produção de leite ajustada a 305 dias de lactação (PL305) de vacas F1 Holandês x Gir variando em função da ordem de partos.

Quanto aos efeitos de ano e de época de parto sobre PLT, PL280 e PL305, as maiores produções foram observadas quando os partos ocorreram na época da seca (Tab. 3), o que pode ser devido à suplementação nessa época, que propicia maiores produções no início da lactação e, consequentemente, maior produção ao final da lactação e nos ajustes (Freitas et al., 2001).

Tabela 3. Médias de características produtivas de vacas F1 Holandês x Gir com teste de médias nas diferentes variáveis classificatórias significativas

\begin{tabular}{|c|c|c|c|c|c|c|c|}
\hline Variáveis classificatórias & & & & & & Médias & \\
\hline & & PLT (kg) & $\begin{array}{l}\text { DL } \\
\text { (dias) }\end{array}$ & $\begin{array}{l}\text { PMD } \\
(\mathrm{kg})\end{array}$ & $\begin{array}{l}\text { PL280 } \\
(\mathrm{kg})\end{array}$ & PL305 (kg) & PLIdP \\
\hline \multicolumn{8}{|l|}{ Época do parto } \\
\hline & Chuvas & 5912,05 & 273,37 & 21,96 & 6053,79 & 6588,01 & 16,32 \\
\hline & Seca & 6498,17 & 289,11 & 22,40 & 6303,46 & 6837,69 & 17,27 \\
\hline \multicolumn{8}{|l|}{ Ano do parto } \\
\hline & 2008 & $6215,42^{\mathrm{b}, \mathrm{c}}$ & $\begin{array}{l}2 / 8,85 \\
295,95^{\mathrm{a}, \mathrm{b}}\end{array}$ & $\begin{array}{l}20,31 \\
21,11^{\mathrm{c}, \mathrm{d}}\end{array}$ & $\begin{array}{l}5 / 34,47^{\circ} \\
5874,57^{c}\end{array}$ & $\begin{array}{l}6268,70^{\circ} \\
640879^{c}\end{array}$ & $\begin{array}{l}15,39^{\mathrm{c}} \\
16,47^{\mathrm{c}, \mathrm{d}}\end{array}$ \\
\hline & 2009 & $6396,21^{\mathrm{b}}$ & $288,97^{\mathrm{a}, \mathrm{b}}$ & $22,12^{b, c}$ & $6204,51^{\mathrm{b}}$ & $6738,73^{\mathrm{b}}$ & $17,15^{\mathrm{b}, \mathrm{c}}$ \\
\hline & 2010 & $5934,01^{\mathrm{c}, \mathrm{d}}$ & $282,01^{\mathrm{a}, \mathrm{b}}$ & $21,16^{\mathrm{c}, \mathrm{d}}$ & $5891,05^{\mathrm{c}}$ & $6425,27^{c}$ & $15,89^{\mathrm{c}, \mathrm{d}}$ \\
\hline & 2011 & $6304,85^{\mathrm{b}}$ & $283,57^{\mathrm{a}, \mathrm{b}}$ & $22,20^{\mathrm{b}, \mathrm{c}}$ & $6228,57^{b}$ & $6762,79^{b}$ & $16,72^{\mathrm{d}}$ \\
\hline & 2012 & $6867,84^{\mathrm{a}}$ & $300,21^{\mathrm{a}}$ & $22,71^{\mathrm{b}}$ & $6435,92^{\mathrm{a}, \mathrm{b}}$ & $6970,14^{\mathrm{a}, \mathrm{b}}$ & $18,60^{\mathrm{a}}$ \\
\hline & 2013 & $6752,55^{\mathrm{a}}$ & $291,14^{\mathrm{a}, \mathrm{b}}$ & $23,24^{\mathrm{a}, \mathrm{b}}$ & $6514,52^{\mathrm{a}, \mathrm{b}}$ & $7048,74^{\mathrm{a}, \mathrm{b}}$ & $18,05^{\mathrm{a}, \mathrm{b}}$ \\
\hline & 2014 & $5954,61^{\mathrm{c}, \mathrm{d}}$ & $250,58^{c}$ & $24,18^{\mathrm{a}}$ & $6583,19^{\mathrm{a}}$ & $7117,41^{\mathrm{a}}$ & $18,22^{a, b}$ \\
\hline
\end{tabular}

Médias seguidas por letras diferentes na coluna dentro de cada variável classificatória diferem entre si pelo teste $\mathrm{t}$ (época do parto) ou teste de Duncan (ano do parto) $(\mathrm{P}<0,05)$.

PLT = produção leiteira total; $\mathrm{DL}=$ duração da lactação; $\mathrm{PMD}=$ produção de leite média diária; PL280 = produção de leite ajustada a 280 dias de lactação; PL305 = produção de leite ajustada a 305 dias de lactação; PLIdP = produção de leite por intervalo de partos. 
A produção média diária de leite acompanha o que ocorre na PLT, com menores produções nas primeiras lactações, aumentando com a maturidade da vaca (Fig. 2). O que coopera para maior rentabilidade da propriedade é a PLIdP se assemelhar à PMD, aproximando-se do cenário considerado ideal, com IdP próximo de 12 meses e DL de 280 dias, como foi observado neste estudo, em que a DL média foi de 283 dias. A PMD e a PLIdP obtidas neste estudo superam as médias encontradas por Glória et al. (2006) e Balancin Júnior et al. (2014), que, ao avaliarem animais F1, obtiveram 9,00 e 9,58kg de PLIdP, respectivamente. Borges et al. (2015) observaram que a PMD na nona lactação foi de $15,7 \mathrm{~kg}$ pelas vacas $\mathrm{F} 1$, sendo inferior à obtida pelas vacas de primeira ordem deste estudo, o que demonstra a elevada produção que esse rebanho expressa.

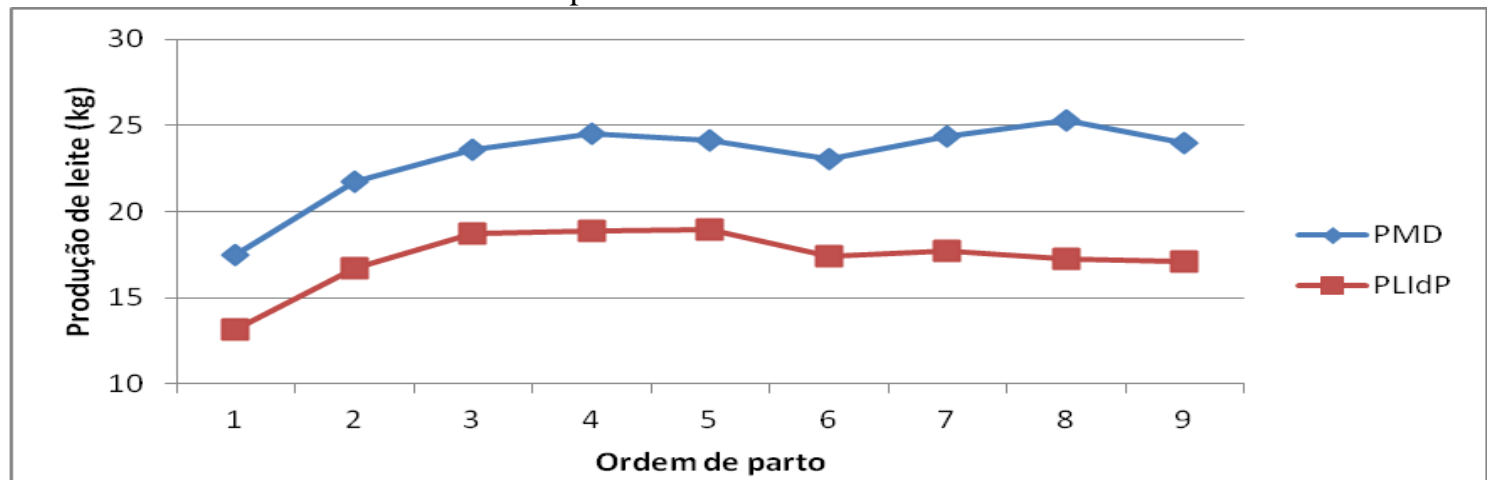

Figura 2. Produção de leite média diária (PMD) e produção de leite por intervalo de partos (PLIdP) de vacas F1 Holandês x Gir variando em função da ordem de partos.

A média da duração da lactação encontrada (Tab. 1) foi inferior às encontradas para vacas da raça Holandês (Mellado et al., 2011; Madalena , 2012). Esse menor período de lactação pode ser devido, em parte, ao período de serviço observado nesse rebanho F1. Não foi observado efeito da ordem de parto sobre a DL (Tab. 2) como houve para ano e estação de parto. Os animais que pariram na seca apresentaram lactação mais longa do que os que pariram na época chuvosa $(289,11$ vs. 273,37 dias $)(\mathrm{P}<0,05$; Tab. 3), oposto do encontrado por Freitas et al. (2001) e Carvalho et al. (2009). O ano do parto também teve influência sobre a DL (Tab. 3). A variação entre os anos foi pequena, reforçando a característica de duração de lactação das vacas F1 como aproximadamente 280 dias. No ajuste a 280 dias de lactação, as produções se aproximam mais da PLT, pois respeita a característica de duração de lactação das vacas $\mathrm{F} 1$, mas, ainda assim, o ajuste para 305 dias funciona como patamar para comparação com as lactações de vacas com maior proporção de genes Holandês e com lactações mais longas.

Quanto às curvas de lactação, analisadas usandose o modelo de Wood, estas apresentaram formato de curva semelhante ao encontrado para vacas leiteiras especializadas de origem europeia
(Fig. 3), caracterizada por uma fase ascendente até o pico e uma fase descendente posterior ao pico, assim como o encontrado por Glória et al. (2010), também trabalhando com vacas F1 HxZ. Já Torquato et al. (2012), que também utilizaram o modelo de Wood para estimar a curva de vacas F1 HxG, encontraram formato atípico para a curva, sem a presença de pico, com tendência linear.

O tempo decorrido até a ocorrência do pico (Tab. 4) também foi semelhante ao encontrado em raças europeias, o qual ocorre entre seis e oito semanas de lactação. Glória et al. (2010) e Santos (2011) apresentaram tempo decorrido até o pico bem inferiores, com 28 e oito dias, respectivamente. Lima (2011) discute que essa diferença entre os períodos até o pico pode ser explicada pelo fato de vacas mestiças terem menores quantidades de células secretoras na glândula mamária para se diferenciarem e entrarem em atividade após o início da lactação. Porém, pelo potencial produtivo observado neste estudo, essa explicação parece não se aplicar, apesar de serem vacas mestiças. Conhecer a conformação da curva é fundamental para realizar ajustes no manejo na intenção de explorar o máximo potencial do rebanho. 


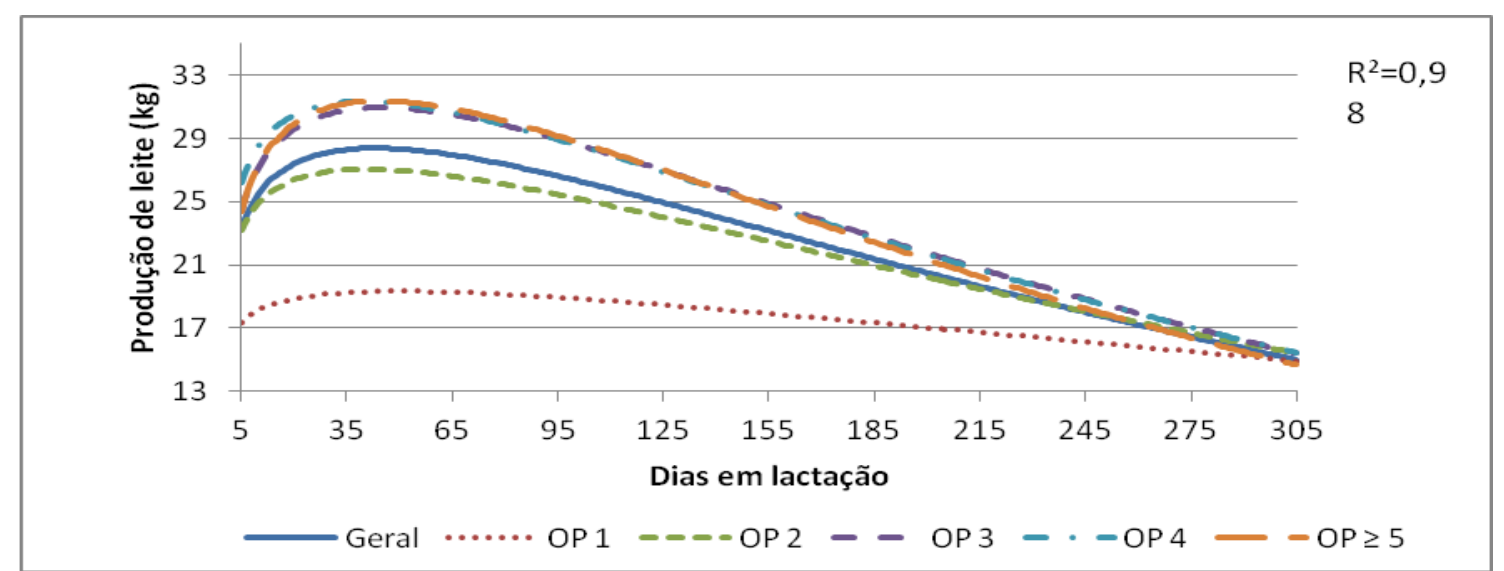

Figura 3. Curvas de lactação de vacas mestiças F1 Holandês x Gir, estimadas pela função gama incompleta, de forma geral e em função da ordem de parto.

Tabela 4. Parâmetros da curva de lactação, produção no pico, tempo até o pico e persistência de lactação de vacas mestiças F1 Holandês x Gir, estimados pela função gama incompleta, de forma geral e em função da ordem de parto

\begin{tabular}{lrrrrrr} 
& Geral & OP 1 & \multicolumn{1}{c}{ OP 2 } & OP 3 & OP 4 & OP $\geq 5$ \\
\hline Parâmetro a & 18,4919 & 15,3794 & 19,2191 & 18,7009 & 20,9294 & 18,2741 \\
Parâmetro b & 0,155 & 0,0786 & 0,1262 & 0,1796 & 0,1511 & 0,1935 \\
Parâmetro c & 0,00359 & 0,00157 & 0,00309 & 0,004 & 0,00383 & 0,00435 \\
Produção acumulada em 305 dias (kg) & 6827,58 & 5303,05 & 6653,71 & 7314,97 & 7341,30 & 7267,41 \\
Produção ao pico (kg) & 28,39 & 19,34 & 27,05 & 30,95 & 31,35 & 31,39 \\
Tempo até o pico (dias) & 43,18 & 50,06 & 40,84 & 44,90 & 39,45 & 44,48 \\
Persistência & 2,82 & 3,02 & 2,83 & 2,83 & 2,78 & 2,82 \\
\hline
\end{tabular}

$\mathrm{a}=$ produção inicial da vaca; $\mathrm{b}=$ taxa de aumento da produção até atingir o pico; $\mathrm{c}=$ taxa de declínio na produção após atingir o pico de produção; $\mathrm{OP}=$ ordem de parto.

A produção inicial (parâmetro a), a taxa de aumento da produção até o pico (parâmetro b) e a produção no pico aumentaram nas maiores ordens de parto, assim como a taxa de declínio após o pico (Tab. 4), resultados semelhantes aos encontrados por Glória et al. (2010). No primeiro e segundo partos, as produções foram inferiores, porém a persistência de lactação, sobretudo na primeira lactação, foi superior, tornando as curvas com declínio menos acentuado (Fig. 3). $\mathrm{Na}$ quarta ordem de parto, as vacas apresentaram as maiores produções em 305 dias e alcançaram o pico mais rapidamente, o que pode ser atribuído à maior produção inicial na lactação indicada pelo parâmetro a (Tab. 4).

Com relação à época de parto (Fig. 4), as curvas das vacas que pariram na estação chuvosa demonstraram maior produção inicial (parâmetro a), com menor taxa de aumento (parâmetro b) até atingirem o pico, e alcançaram o pico mais cedo, além da menor persistência de lactação. As lactações iniciadas na época da seca apresentaram maior persistência e maior produção acumulada (Tab. 5), apesar da menor produção inicial, o que pode ser devido à suplementação feita nessa época.

As curvas em função dos períodos de serviço (Fig. 5) foram feitas com base na duração média de lactação de cada uma das classes formadas. Com isso, fica evidente que as vacas com menor PS secaram mais cedo, respeitando-se o período de serviço de 60 dias e a preparação para a próxima lactação, apresentando menor persistência (Tab. 6). Em consequência, a produção acumulada aumenta com os maiores períodos de serviço, apesar da menor produção inicial (parâmetro a) e do maior tempo até atingir o pico. 


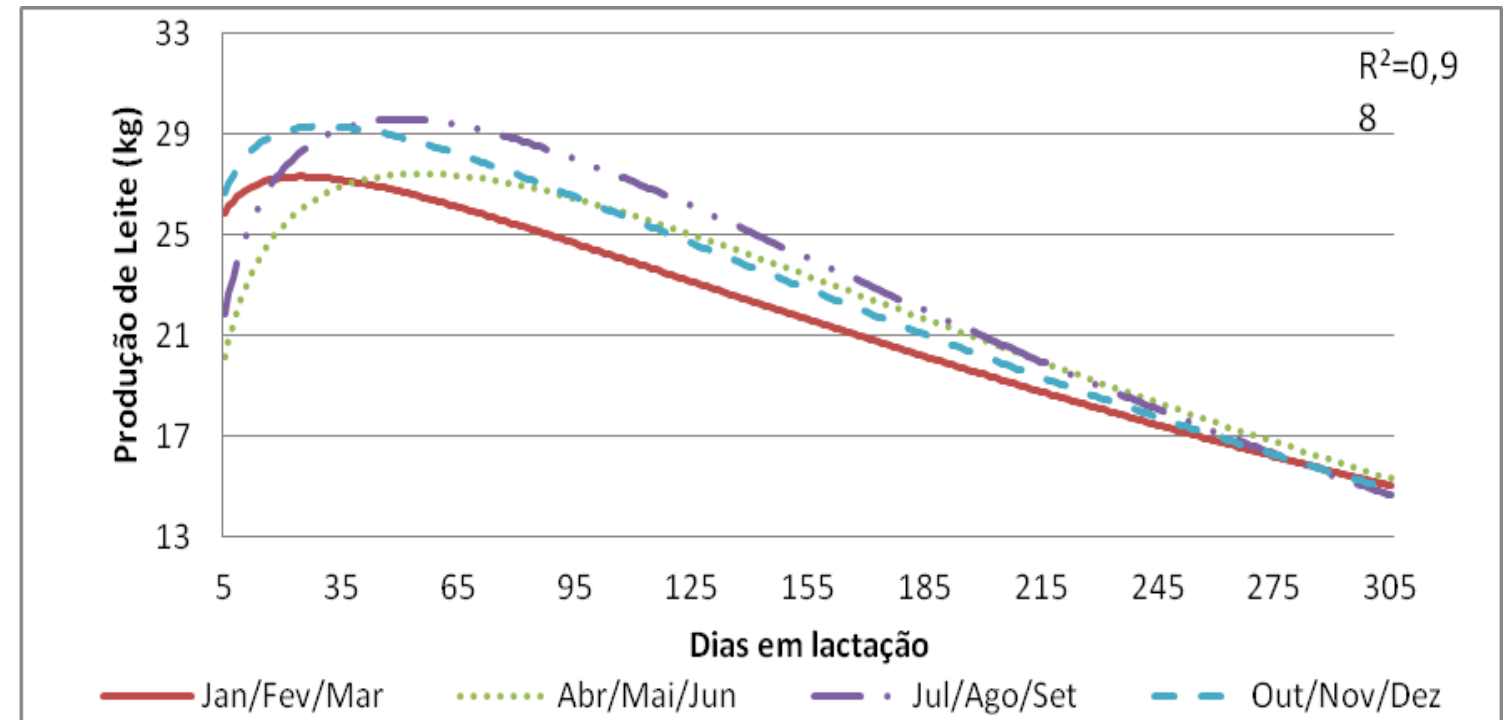

Figura 4. Curvas de lactação de vacas mestiças F1 Holandês x Gir, estimadas pela função gama incompleta, em função da época de parto.

Tabela 5. Parâmetros da curva de lactação, produção no pico, tempo até o pico e persistência de lactação de vacas mestiças F1 Holandês x Gir, estimados pela função gama incompleta, em função da época de parto

\begin{tabular}{lrrrr} 
& & & & \\
\hline Parâmetro a & Jan/Fev/Mar & Abr/Mai/Jun & Jul/Ago/Set & Out/Nov/Dez \\
Parâmetro b & 23,551 & 14,698 & 15,791 & 23,0942 \\
Parâmetro c & 0,0673 & 0,2074 & 0,2154 & 0,0994 \\
Produção acumulada em 305 dias (kg) & 0,00274 & 0,00376 & 0,00429 & 0,00331 \\
Produção ao pico (kg) & 6507,88 & 6768,76 & 7010,11 & 6845,45 \\
Tempo até o pico (dias) & 27,31 & 27,44 & 29,60 & 29,32 \\
Persistência & 24,56 & 55,16 & 50,21 & 30,03 \\
\hline
\end{tabular}

$\mathrm{a}=$ produção inicial da vaca; $\mathrm{b}=$ taxa de aumento da produção até atingir o pico; $\mathrm{c}=$ taxa de declínio na produção após atingir o pico de produção.

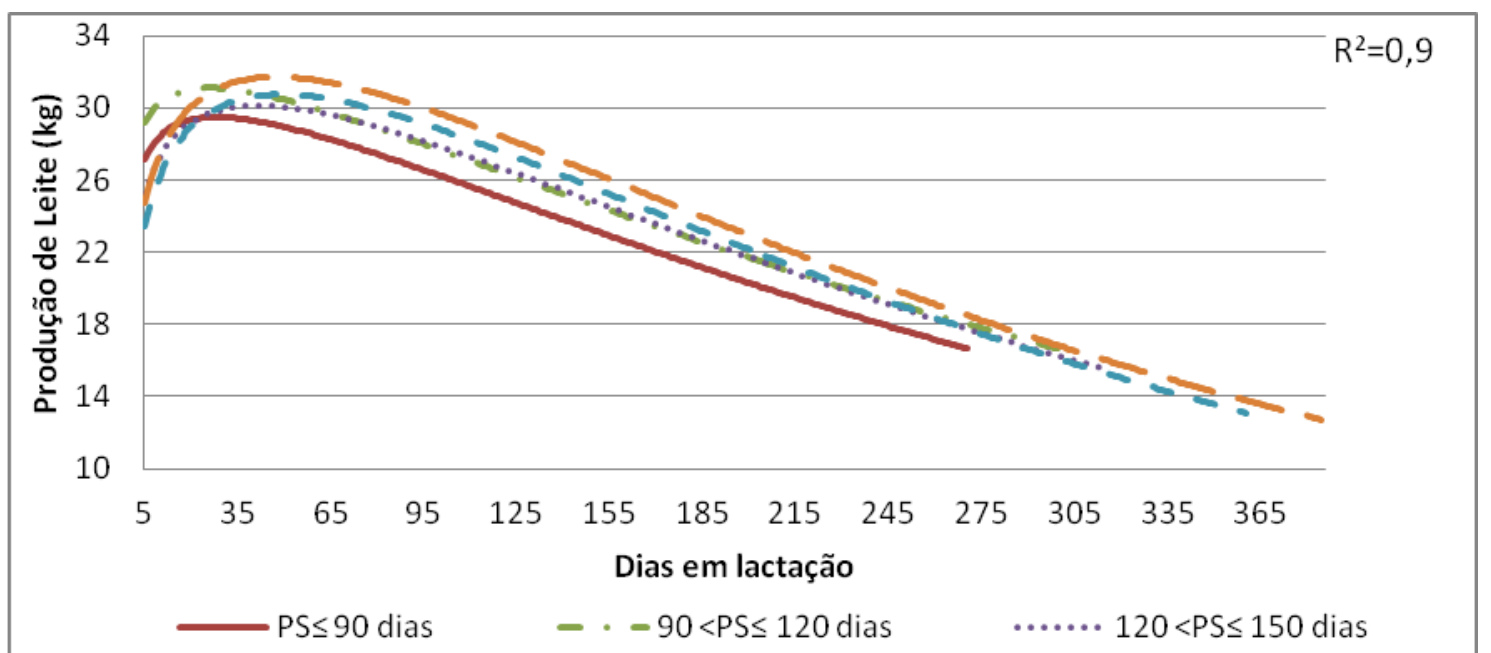

Figura 5. Curvas de lactação de vacas mestiças F1 Holandês x Gir, estimadas pela função gama incompleta, em função das classes de períodos de serviço. 
Tabela 6. Parâmetros da curva de lactação, da produção no pico, do tempo até o pico e da persistência de lactação de vacas mestiças F1 Holandês x Gir, estimados pela função gama incompleta, em função das classes de período de serviço

\begin{tabular}{lrrrrr} 
& PS até & PS=91 a & PS= 121 a & PS= 151 a & PS maior que \\
& $90 \mathrm{~d}$ & $120 \mathrm{~d}$ & $150 \mathrm{~d}$ & $180 \mathrm{~d}$ & $180 \mathrm{~d}$ \\
\hline Parâmetro a & 23,903 & 26,194 & 20,333 & 17,4527 & 18,8047 \\
Parâmetro b & 0,0898 & 0,0764 & 0,1444 & 0,1958 & 0,1827 \\
Parâmetro c & 0,0032 & 0,00297 & 0,0035 & 0,004 & 0,00385 \\
Médias de dias em lactação & 270,00 & 304,31 & 314,84 & 360,30 & 384,23 \\
Produção acumulada nos dias em & 6326,37 & 7297,15 & 7377,32 & 8152,49 & 8766,65 \\
lactação (kg) & & & & & \\
Produção ao pico (kg) & 29,48 & 31,10 & 30,11 & 30,74 & 31,71 \\
Tempo até o pico (dias) & 28,06 & 25,72 & 41,26 & 48,95 & 47,45 \\
Persistência & 2,72 & 2,72 & 2,81 & 2,87 & 2,86 \\
\hline
\end{tabular}

$\mathrm{a}=$ produção inicial da vaca; $\mathrm{b}=$ taxa de aumento da produção até atingir o pico; $\mathrm{c}=$ taxa de declínio na produção após atingir o pico de produção; PS = período de serviço; $\mathrm{d}=$ dias.

\section{CONCLUSÕES}

As médias obtidas no estudo desse rebanho apresentam bons resultados, com elevadas eficiência reprodutiva e produção de leite. As fêmeas F1 são boa alternativa para a produção de leite, podendo atingir elevada produção com padrão de curva semelhante ao encontrado em raças especializadas. $\mathrm{O}$ resultado foi propiciado pelas boas condições de manejo adotado na propriedade, bem como pela utilização predominante de matrizes oriundas de programas de cruzamento direcionados utilizando critérios de melhoramento genético.

\section{REFERÊNCIAS}

BALANCIN JÚNIOR, A.; PRATA, M.A.; MOREIRA, H.L. et al. Avaliação de desempenho produtivo e reprodutivo de animais mestiços do cruzamento Holandês x Gir. Bol. Ind. Anim., v.71, p.357-364, 2014.

BANCO de Dados meteorológicos para ensino e pesquisa- dados históricos. [Brasília]: INMET, 2016. Disponível em: <http://www.inmet.gov.br/ portal/index.php?r=bdmep/bdmep>. Acessado em outubro de 2016.

BORGES, A.M.; MARTINS, T.M.; NUNES, P.P.; RUAS, J.R.M. Reprodução de vacas mestiças: potencialidade e desafios. Rev. Bras. Reprod. Anim, v.39, p.155-163, 2015.

CAMPOS, O.F.; MIRANDA, J.E.C. Gado de leite: o produtor pergunta, a Embrapa responde. 3.ed. Brasília: EMBRAPA, 2012. 311p.
CARVALHO, B.C.; RUAS, J.R.M.; SILVA FILHO J.M. et al. Avaliação de diferentes manejos pré-parto sobre o peso e o escore da condição corporal de vacas mestiças F1 Holandês x Zebu. Rev. Bras. Cienc. Vet., v.16, p.62-67, 2009.

DELGADO, P.A.M.; CALDERÓN, L.G.R.; ALDANA, A.M.; PENAGOS, C.E.L. Desempeño productivo y reproductivo de vacas F1 Gyr x Holstein en clima cálido colombiano. Arq. Bras. Med. Vet. Zootec., v.6, p.17-23, 2012.

FERREIRA, A.M.; MIRANDA, J.E.C. Medidas de eficiência da atividade leiteira: índices zootécnicos para rebanhos leiteiros. Juiz de Fora: EMBRAPA, 2007. 8p. (Comunicado técnico, n.54).

FREITAS, M.S.; DURÃES, M.C.; FREITAS, A.F.; BARRA, R.B. Comparação da produção de leite e de gordura e da duração da lactação entre cinco "graus de sangue" originados de cruzamentos entre Holandês e Gir em Minas Gerais. Arq. Bras. Med. Vet. Zootec., v.53, p.708-713, 2001.

GLÓRIA, J.R.; BERGMANN, J.A.G.; QUIRINO, C.R. et al. Curvas de lactação de quatro grupos genéticos de mestiças Holandês $\mathrm{X}$ Zebu. Rev. Bras. Zootec., v.39, 2010.

GLÓRIA, J.R.; BERGMANN, J.A.G.; REIS, R.B. et al. Efeito da composição genética e de fatores de meio sobre a produção de leite, a duração da lactação e a produção de leite por dia de intervalo de partos de vacas mestiças Holandês-Gir. Arq. Bras. Med. Vet. Zootec., v.58, p.1139-1148, 2006. 
LEMOS, A.M.; TEODORO, R.L.; MADALENA, F.E. Comparative performance of six HolsteinFriesian x Guzera grades in Brazil. 9. Stayability, herd life and reasons for disposal. Rev. Bras. Genét., v.19, p.259-264, 1996.

LIMA, J.A.M. Desempenho produtivo de vacas F1 Holandês/Zebu submetidas ao aumento do número de ordenha no início da lactação e a diferentes manejos de amamentação. 2011. 79f. Dissertação (Mestrado em Zootecnia) Universidade Federal de Minas Gerais, Belo Horizonte, MG.

MADALENA, F.E. A contribuição da F1 de gado de leite e as estratégias de sua utilização. In: SIMPÓSIO BRASILEIRO DE MELHORAMENTO ANIMAL, 9., 2012, João Pessoa. Anais ... João Pessoa: SBMA, 2012. 13p.

MELLADO, M.; CORONEL, F.; ESTRADA, A.; RIOS, F.G. Lactation performance of Holstein and Holstein $x$ Gyr cattle under intensive condition in a subtropical environment. Trop. Subtrop. Agroecosyst., v.14, p.927-931, 2011.

NATIONAL research council -NRC Nutrient requiriments of dairy cattle. 7ed. Washinton, D. C.: NationalAcademic Press. 381p., 2001.

PRATA, M.A.; PEREIRA, M.C.; FARO, L. et al. Efeito do intervalo de partos sobre a eficiência produtiva e econômica em rebanhos gir leiteiro. Bol. Ind. Anim.,v.71, p.1-7, 2014.

PROGRAMA de melhoramento genético da raça girolando - sumário de touros. Juiz de Fora: Embrapa Gado de Leite, 2016. 72p.
RELATÓRIO anual. [s.l.]: Associação Brasileira de Criadores de Bovinos da Raça Holandesa. 2014.

RUAS, J.R.M.; CARVALHO, B.C.; SILVA FILHO, J.M. Efeito da base genética materna e da estação de parição sobre variáveis produtivas de fêmeas primíparas Holandês x Zebu. Arq. Bras. Med. Vet. Zootec., v.59, p.218-224, 2007

RUAS, J.R.M.; SILVA, E.A.; QUEIROZ, D.S. et al. Características produtivas da lactação de quatro grupos genéticos F1 Holandês x Zebu. Rev. Bras. Cienc. Vet., v.21, p.33-37, 2014.

SANTOS, S.A. Curvas de lactação e consumo de vacas F1 Holandês x Zebu em pastejo e em confinamento. 2011. 192f. Tese (Doutorado em Zootecnia) - Universidade Federal de Viçosa, Viçosa, MG.

STATISTICAL analysis system. Version 9.0. Cary: SAS Institute, 2004. 5135p.

TEODORO, L.T. Pesquisa em cruzamentos e resultados zootécnicos. Cad. Téc. Esc. Vet. $U F M G, \mathrm{n} .18,1996.8 \mathrm{p}$.

TORQUATO, I.A.; FARO, L.E.; MASCIOLI A.S. Curvas de lactação de fêmeas Girolando da região Agreste de Pernambuco. In: SIMPÓSIO BRASILEIRO DE MELHORAMENTO ANIMAL, 9., 2012, João Pessoa. Anais ... João Pessoa: SBMA, 2012.

WOOD, P.D.P. Algebric model of lactation curve in cattle. Nature, v.216, p.164-165, 1967. 